Kamil Krasuski

\title{
APPLICATION THE SINGLE DIFFERENCE TECHNIQUE IN AIRCRAFT POSITIONING USING THE GLONASS SISTEM IN THE AIR TRANSPORT
}

The article presents the possibility of using the Between Satellite Single Difference method (BSSD) in the precise determination of the aircraft position in the Global Navigation Satellite System GLONASS navigation system. The paper presents the mathematical model of the BSSD method, describes the research test and presents the results of conducted examinations. The research test was conducted within the implementation of the GLONASS satellite technique in air navigation. The test research uses the actual GLONASS navigation data registered by the Topcon HiperPro receiver, mounted onboard a Cessna 172 aircraft. Obtained findings of the research work are interesting from the perspective of implementation of the GLONASS satellite technique in aviation. It should be emphasized that standard deviations of the determined position of the Cessna 172, using the BSSD method, do not exceed $2 \mathrm{~m}$. The article also determines the accuracy of a position of the Cessna 172 in the GLONASS solution with reference to a solution in the GPS navigation system.

Keywords: GLONASS, ICAO, accuracy, GPS, aviation test

\section{Introduction}

Numbers of aeronautical operations in the air transport are still growing up on the world [1]. In addition, the aircraft position in different phase of flight should be permanently monitored in aeronautical operation [2-3]. The GNSS satellite technique is applied in monitoring of aircraft position in the air transport. The concept of using the GNSS satellite navigation systems in aviation has been developed and implemented by the ICAO [4]. In accordance with the ICAO recommendations, the GNSS satellite systems only supplement on-board aircraft avionics. In order to improve the performance of GNSS navigation systems, it is necessary to implement the augmentation products for conducting the air navigation. The ICAO has identified certification for the GPS and GLONASS satellite systems as additional systems for on-board avionics. Moreover, in order to improve the performance of GNSS navigation systems in aviation, the ICAO organization implemented ABAS, SBAS, GBAS augmentation systems [5]. The GLONASS satellite system can be used as an independent navigation sensor used in precise aircraft positioning [6], an external module for the ABAS augmentation system coupled with the RAIM controller belonging to the computational subassemblies of the on-board computer FMS [7], navigation sensor working with the geostationary satellite systems, which is to facilitate positioning in the SBAS system [8], navigation sensor working with ground radio systems, which support positioning in the GBAS system [9], acting as the hybrid GNSS/INS navigation system [10]. The GLONASS satellite system plays a major role in the air navigation, complementing the NAVSTAR GPS navigation system. It should be noted that the GLONASS system is constantly being upgraded, thus the number of satellites in the GLONASS constellation is often changing [11].

The main aim of this article is to assess the accuracy and reliability of determining an aircraft position in the GLONASS system. In particular, in the numerical analysis the authors attempted at recovering the position of the Cessna 172 during a test flight over the aerodrome EPDE in Deblin, Poland. The position of the Cessna 172 is calculated based on the differential positioning BSSD method (Difference Between Single Satellite) for the GLONASS code observations. The test research uses the GLONASS code observations registered by the Topcon HiperPro receiver, mounted on-board the Cessna 172 aircraft. The article is divided into 5 parts: part one is an introduction relating to description of research problems, part two is a description of the research BSSD model, chapter three is a description of the research experiment, section four contains research results and discussion, chapter five comprises final conclusions.

\section{Mathematical model of the BSSD method in the GLONASS system}

The basic equation of the mathematical model for the BSSD positioning method can be represented as follows [12]:

$$
\begin{aligned}
\Delta P 1_{i j}= & \Delta \rho_{i j}+c \cdot \Delta d t s_{j i}+\Delta I_{i j}+\Delta T_{i j}+ \\
& +\Delta S I F C B_{i j, L 1}+\Delta M_{i j, L 1}
\end{aligned},
$$

Kamil Krasuski*

Department of Air Navigation, Faculty of Aviation and Aeronautics, Polish Air Force University, Deblin, Poland

"E-mail of corresponding author: k.krasuski@law.mil.pl 
where: $\Delta$ - the single difference operator for the GLONASS code measurements allows determining the difference in code measurements from two satellites tracked by one receiver in the same measurement period,

$P 1_{i j}=P 1_{i}-P 1_{j}$ - the value of a single code difference between satellites $i$ and $j$ on L1 frequency in the GLONASS system (expressed in meters),

$i$ - GLONASS satellite index,

$j$ - GLONASS satellite index,

$c$ - light speed (expressed in $\mathrm{m} / \mathrm{s}$ ),

$\rho_{i j}=\rho_{i}-\rho_{j}$ - difference in geometry distance between satellites $i$ and $j$ on L1 frequency in the GLONASS system (expressed in meters),

$$
\begin{aligned}
& \rho_{i}=\sqrt{\left(x-X_{i}\right)^{2}+\left(y-Y_{i}\right)^{2}+\left(z-Z_{i}\right)^{2}}, \\
& \rho_{j}=\sqrt{\left(x-X_{j}\right)^{2}+\left(y-Y_{j}\right)^{2}+\left(z-Z_{j}\right)^{2}},
\end{aligned}
$$

$(x, y, z)$ - coordinates of the aircraft in the XYZ geocentric frame (expressed in meters),

$\left(X_{i}, Y_{i}, Z_{i}\right)-i$-th satellite coordinates in the GLONASS system (expressed in meters),

$\left(X_{j}, Y_{j}, Z_{j}\right)-j$-th satellite coordinates in the GLONASS system (expressed in meters),

$d t s_{j i}$ - difference in satellites tracking between $i$ and $j$ satellites on L1 frequency in theGLONASS system (expressed in seconds),

$I_{i j}$ - difference in ionosphere delay between $i$ and $j$ satellites on L1 frequency in GLONASS system (expressed in meters), $T_{i j}$ - difference between values of the troposphere delay between satellites $i$ and $j$ on L1 frequency in the GLONASS system (expressed in meters),

$S I F C B_{i j, L 1^{-}}$difference between Satellite Inter-Frequency Code Biases values between satellites $i$ and $j$ on L1 frequency in the GLONASS system (expressed in meters), $M_{i j, L 1}$ - difference in value of multipath effect and measurement noise between satellites $i$ and $j$ on $\mathrm{L} 1$ frequency in the GLONASS system (expressed in meters).

Equation (1) is resolved on the basis of the method of least squares as below [13]:

$$
\left\{\begin{array}{c}
\mathbf{Q}_{\mathbf{x}}=\mathbf{N}^{-1} \cdot \mathbf{L} \\
\mathbf{v}=\mathbf{A} \cdot \mathbf{Q}_{\mathbf{x}}-\mathbf{d} \mathbf{l} \\
m 0_{\text {post }}=\sqrt{\frac{[\mathbf{p v v}]}{n-k}}, \\
\mathbf{C}_{\mathbf{Q x}}=m 0_{\text {post }}^{2} \cdot \mathbf{N}^{-1} \\
\mathbf{m}_{\mathbf{Q x}}=\operatorname{diag}\left(\sqrt{\mathbf{C}_{\mathbf{Q x}}}\right)
\end{array}\right.
$$

where:

$\mathbf{Q}_{\mathrm{T}}$ - vector with unknown parameters;

$\mathbf{N}=\mathbf{A}^{\mathrm{T}} \cdot \mathbf{p} \cdot \mathbf{A}$ - matrix of the normal equations frame;

A - matrix of coefficients, matrix is full rank;

p - matrix of weights;

$\mathbf{L}=\mathbf{A}^{\mathbf{T}} \cdot \mathbf{p} \cdot \mathbf{d l}$ - vector of absolute terms;

dl - vector with difference between measurements and modelled parameters;

$m 0_{\text {post }}$ - standard error of unit weight a posteriori;

$n$ - number of observations in each measurement period; $k$ - number of designated parameters in each measurement epoch;

$\mathbf{v}$ - vector of residuals;

$\mathbf{C}_{\mathbf{Q x}}$ - variance-covariance matrix of parameters designated in the XYZ geocentric frame;

$\mathbf{m}_{\mathbf{Q x}}$ - standard deviations of the designated parameters referenced to the XYZ geocentric frame.

In the least squares method, the aircraft coordinates are determined as parameters $(x, y, z)$ referred to the geocentric frame XYZ. It should be stressed that, due to a single difference operator from the observation Equation (1), the parameter of the receiver clock error is eliminated as a product of the precise time transfer. It is also worth noting that from the difference of the observation Equation (1), the Receiver Inter-Frequency Code Bias (RIFCB) was eliminated, as well, specifying the time of the code signal travelling from the phase centre of the receiver antenna to the onboard receiver oscillator. It must be mentioned that use of a single difference operator reduces the influence of atmospheric delays (ionospheric and tropospheric delays) to determine the position of the aircraft. Moreover, in the process of developing the GLONASS code observations, it is possible to exploit the IGS precision products, such as precise satellite orbits and satellite clocks, which increase aircraft positioning accuracy. The multipath parameter in the computation process may be determined from the model or disregarded when developing the GLONASS observations. A key element in the method of least squares is to determine the aircraft positioning precision. Precision is determined by parameters of standard deviation $\mathbf{m}_{\mathbf{Q x}}$ for all the three designated aircraft coordinates. The process of determining an aircraft position is conducted using a stochastic model in the method of least squares. In addition, the position of an aircraft is determined in an iterative process, taking into account the value of the coefficient of variation $m 0_{\text {post }}$.

\section{Research experiment}

The practical application of the BSSD positioning method for the GLONASS satellite system in the air navigation was verified and subjected to a thorough analysis for the navigation data derived from the experiment conducted in Deblin, in south-east Poland. In the air experiment, the operation and use of the GNSS navigation systems for the airport EPDE in Deblin, Poland underwent testing. In the air experiment, the aircraft Cessna 172 was used to make a trial flight around the airport EPDE in Deblin. It needs to be mentioned that on board the Cessna 172 in the cockpit, there was a dual frequency receiver Topcon HiperPro. Due to the GPS/GLONASS satellite observations, stored and registered by the receiver Topcon HiperPro, it was possible to recover the position of the aircraft Cessna 172 in the post-processing mode. The numerical calculations to determine the position of the Cessna 172 were made in the author's original software APS (Aircraft Positioning Software) Toolbox 
[14]. The APS programme (Aircraft Positioning Software) was written in the language Scilab 6.0.0 environment for the Windows operating system. The APS is a free programming tool to develop kinematic GNSS observations in the post-processing mode. The APS programme enables implementation of the GNSS code observations for the GPS and GLONASS systems. Furthermore, the APS software has 4 basic calculation modules and one descriptive module, i.e.: SPP (Single Point Positioning) module: absolute positioning with L1-C/A code observations in the satellite systems GPS and GLONASS; BSSD SPP (Between Single Satellite Difference of SPP) module: a single difference technique of the code observations L1-C/A in the navigation systems GPS and GLONASS within the SPP positioning method; IF LC (Ionosphere-Free linear combination) module: linear combination "Ionosphere-Free" for P1/P2 code observations in the satellite systems GPS and GLONASS; BSSD IF LC (Difference Between Single Satellite of IF LC) module: a single difference technique of the linear combination "Ionosphere-Free" for the code observations P1/P2 in the navigation system GPS and GLONASS; Info module: text module with a description of the operation and functioning of the APS programme. In the presented scientific article, the P1 code observations in the GLONASS system were used to recover the position of the Cessna 172 in the APS programme. For the sake of making numeric calculations, the "APS programme was configured as follows [14]:

- GNSS system: GLONASS system,

- type of observations: P code at $1^{\text {st }}$ frequency,

- $\quad$ type of RINEX file: 2.10 ,

- $\quad$ source of satellite ephemeris data: precise ephemeris from the IGS service,

- $\quad$ source of satellite clock data: precise ephemeris from the IGS service,

- method of satellite position computation: 9-degrees Lagrange polynomial,

- method of the satellite clock bias computation: 9-degrees Lagrange polynomial,

- the satellite clock bias correction: satellite clock bias from precise ephemeris is corrected using InterFrequency Code Biases for code observations in the BSSD method,

- effect of Earth rotation and time of pseudorange travelling through atmosphere: applied,

- relativistic effect: applied,

- ionosphere source: Klobuchar model,

- troposphere source: Simple model,

- Satellite Inter-Frequency Code Biases (SIFCB): applied,

- instrumental bias for receiver: eliminated,

- receiver clock bias: eliminated,

- multipath and measurement noise: not applied,

- $\quad$ satellite and receiver phase center offset: based on ANTEX file from IGS service,

- Sagnac effect: applied,

- cutoff elevation: $5^{0}$,

- positioning mode: kinematic,

- computation mode: post-processing,
- mathematical model of solution: least square estimation in iterative scheme,

- adjustment processing: applied,

- maximum number of iteration in single measurement epoch: $\mathrm{N}=10$,

- number of unknown parameters: $\mathrm{k}=3$, for each measurement epoch,

- number of observations: $\mathrm{n}>3$, for each measurement epoch,

- interval of computations: $1 \mathrm{~s}$,

- initial coordinates of aircraft position: based on header of the RINEX file,

- time of GNSS system: GPS Time,

- reference frame: IGS'08,

- format of output coordinates: geocentric XYZ and ellipsoidal BLh,

- local test of residuals: applied,

- global statistical test: test Chi-square,

- value of $m 0$ after adjustment processing: $m 0_{\text {post }} \in(0.9: 1.1)$,

- $\quad$ significance level: $(1-\alpha)=0.95$,

- DOP coefficients: estimated,

- $\quad$ coefficients value for HPL and VPL level: $k_{H P L}=6.18$ and $k_{V P L}=5.33$.

\section{Results and discussion}

This section of the study presents the results of positioning the Cessna 172, based on the GLONASS observations for the BSSD method in the APS programme. The numerical analysis for Figures 1 and 2 concerns with determination of the internal reliability and precision of the Cessna 172 positioning for the research BSSD method in the GLONASS system. Figure 1 shows the average error values of the Cessna 172 as parameters of the standard deviation for the designated coordinates of the aircraft $(x, y, z)$. Values of the parameters in Figure 1 are respectively: $m x$ standard deviation along the $\mathrm{X}$ axis, $m y$ - standard deviation along the $\mathrm{Y}$ axis, $m z$ - standard deviation along the $\mathrm{Z}$ axis. Values of the parameters $(m x, m y, m z)$ are determined from the vector $\mathbf{m}_{\mathbf{Q x}}$, as shown below [15]:

$m x=\mathbf{m}_{\mathbf{Q x}}(1,1) ; m y=\mathbf{m}_{\mathbf{Q \mathbf { x }}}(2,1) ; m z=\mathbf{m}_{\mathbf{Q \mathbf { x }}}(3,1)$,

Values of the parameter $m x$ range from $0.1 \mathrm{~m}$ to $1.5 \mathrm{~m}$. Furthermore, the mean value of the parameter $m x$ is equal to $0.4 \mathrm{~m}$, with the statistical median also being equal to $0.4 \mathrm{~m}$. Values of the parameter $m y$ range from $0.1 \mathrm{~m}$ to $1.2 \mathrm{~m}$. Furthermore, the mean value of the parameter $m y$ is approximately $0.3 \mathrm{~m}$, with the statistical median also being equal to $0.3 \mathrm{~m}$. Values of the parameter $m z$ range from $0.1 \mathrm{~m}$ to $1.8 \mathrm{~m}$. Moreover, the mean value $m z$ of the parameter is equal to $0.5 \mathrm{~m}$, with the statistical median also being equal to $0.5 \mathrm{~m}$. It should be emphasized that over $99 \%$ of all the parameter results $(m x, m y, m z)$ do not exceed the level of $1 \mathrm{~m}$.

Figure 2 shows values of the dilution of precision (DOP) coefficients for the performed experimental test. It 


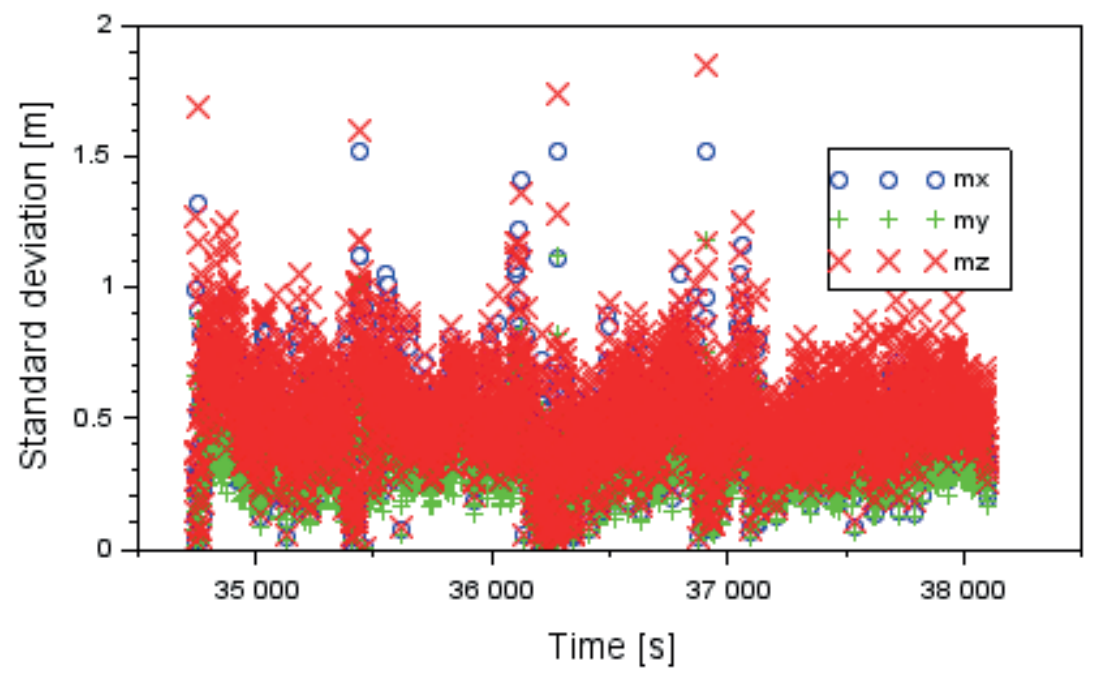

Figure 1 Standard deviations of the Cessna 172 in the XYZ geocentric frame

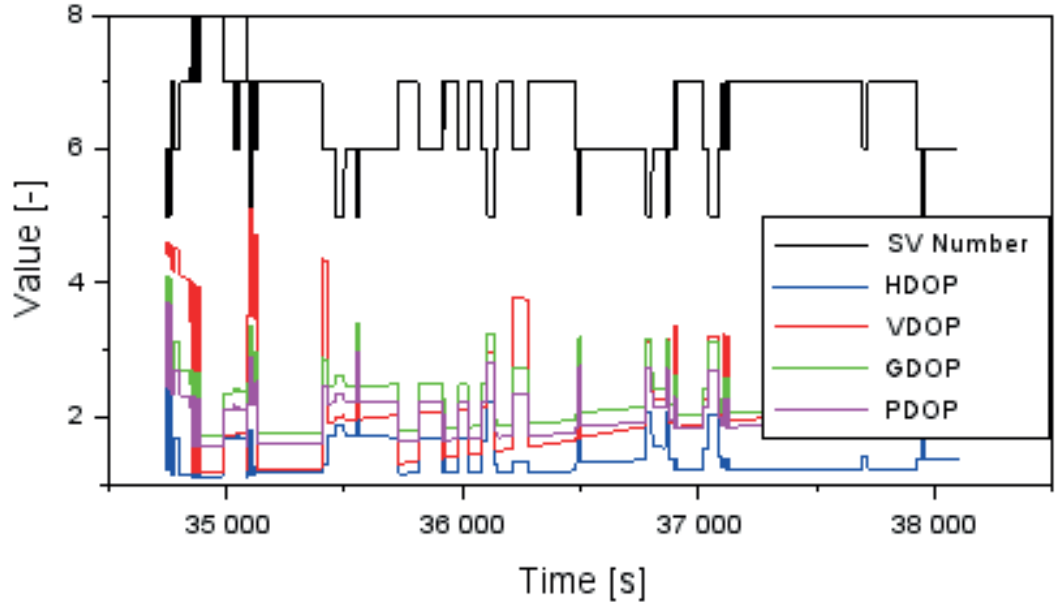

Figure 2 Results of the DOP coefficients

should be stressed that values of the dilution of precision are presented as a function of number of the visible GLONASS satellites. Overall, in Figure 2 the DOP coefficients are in the form of parameters: GDOP, HDOP, PDOP and VDOP $[14,16]$. The value of the GDOP parameter ranges from 1.7 to 4.1 . In addition, the average GDOP value is 2.2 , with the median being equal to 2.1. The value of the PDOP parameter ranges from 1.5 to 3.7. In addition, the average PDOP value is 2.0 , with the median being equal to 1.9 . The value of the HDOP parameter ranges from 1.1 to 3.0. Moreover, the average HDOP value is 1.4 , with the median being equal to 1.2. The value of the VDOP parameter ranges from 1.1 to 5.1. In addition, the average VDOP parameter value is approximately 2.0, with the median also being equal to 2.0.

Figure 2 also shows changes in the availability parameter of the navigation solution of the aircraft position in the form of a number of tracked GLONASS satellites. In this case, the number of GLONASS satellites being tracked ranged from 5 to 8 during the test flight. However, the number of GLONASS satellites facilitated continuous satellite positioning in the air transport, which means that the parameter of availability was $100 \%$ during the air experiment. Maintaining the availability parameter is vitally important in the air transport, as it ensures continuous tracking of the GLONASS signals by the onboard navigation receiver, for the pilot.

Figure 3 shows the HPL and VPL values, obtained for navigation calculations, using the GLONASS navigation system. The HPL parameter values were determined based on the relationship [17]:

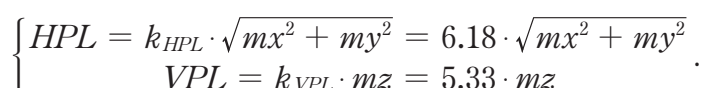

The HPL parameter values range from $0.1 \mathrm{~m}$ to $9.2 \mathrm{~m}$. On the other hand, the VPL parameter values range from $0.1 \mathrm{~m}$ to $11.8 \mathrm{~m}$. The average value of the HPL parameter equals $2.7 \mathrm{~m}$, whereas for the VPL parameter, it is $3.3 \mathrm{~m}$. The parameters HPL and VPL specify the level of reliability of the designated aircraft position in the air transport. It can be concluded that the obtained HPL and VPL safety levels are very good and relatively low. The smaller the value of the HPL and VPL levels, the more reliable it is to determine the position of the aircraft. The reliability of HPL and 


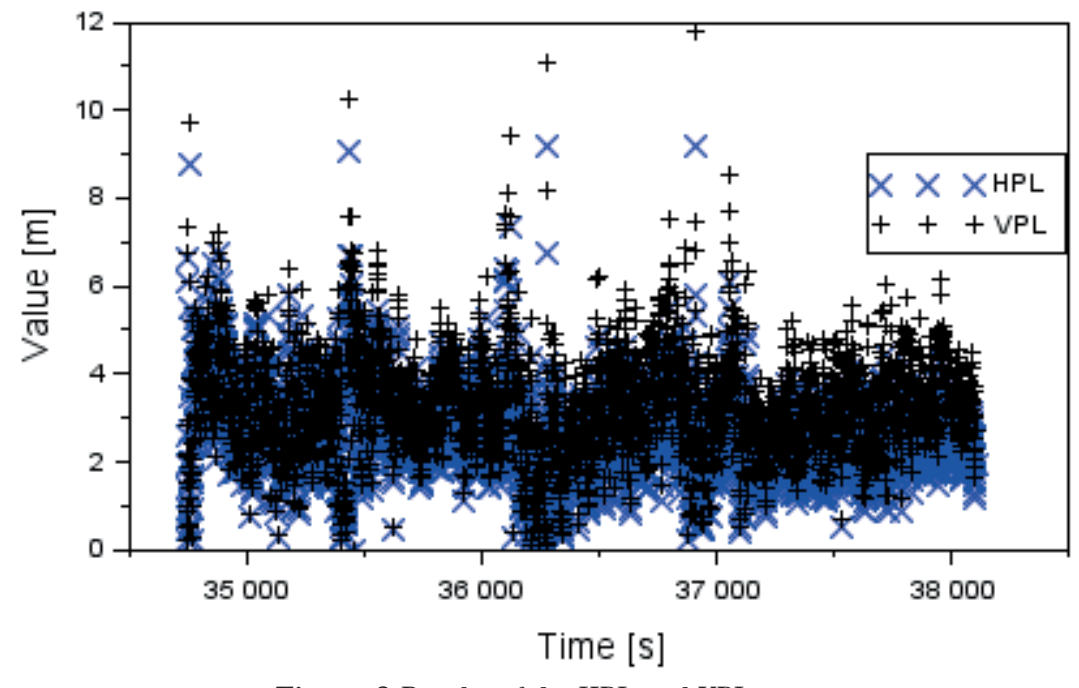

Figure 3 Results of the HPL and VPL terms

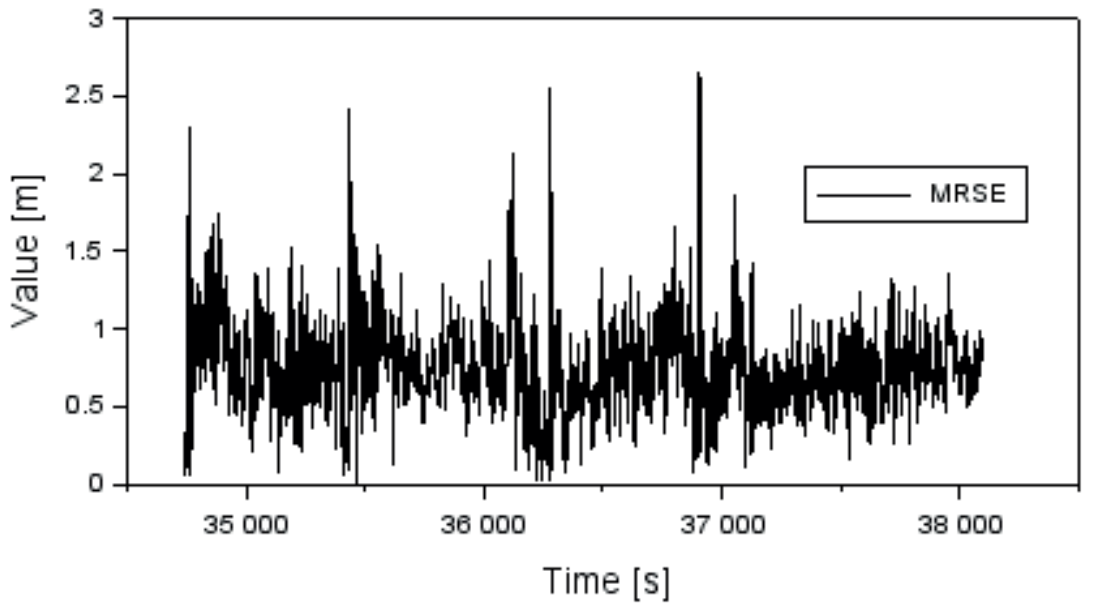

Figure 4 Results of the MRSE term

VPL safety levels is, in the age of the air transport, a key parameter of quality of the satellite positioning in aviation.

Figure 4 shows results of the MRSE parameter, specifying the resultant error of the Cessna 172 position in the 3D space. The MRSE parameter can be calculated from the mathematical formula [15-16]:

$$
M R S E=\sqrt{m x^{2}+m y^{2}+m z^{2}} .
$$

The values of the MRSE parameter in the conducted experimental test ranged from $0.1 \mathrm{~m}$ to $2.7 \mathrm{~m}$. Besides that, the average value of the MRSE parameter is $0.8 \mathrm{~m}$, with the statistical median being equal to $0.7 \mathrm{~m}$. It must be stressed that over $84 \%$ of all the results of the MRSE parameter do not exceed the level of $1 \mathrm{~m}$ and approximately $99 \%$ of all the results of the MRSE parameter do not exceed the limit of $2 \mathrm{~m}$

At a later stage, the authors determined the accuracy of designating the Cessna 172 coordinates for the BSSD method, in the GLONASS system. In particular, the authors made a comparison of the designated coordinates of the Cessna 172 in the GLONASS system to the solution in the GPS navigation system for the same research method. The
GPS navigation solution of the Cessna 172 position for the BSSD research method has also been designated in the APS Toolbox software package. In the assessment of the accuracy of solutions of the Cessna 172, a comparison of geocentric coordinates $(x, y, z)$ in the GLONASS and GPS solution was made. Moreover, the difference for these coordinates was determined, see below [18]:

$$
\begin{aligned}
d x & =x_{G L O}-x_{G P S} \\
d y & =y_{G L O}-y_{G P S} \\
d z & =z_{G L O}-z_{G P S}
\end{aligned}
$$

where:

$x_{G L O}-\mathrm{x}$ coordinate of aircraft based on the GLONASS solution, see Equation (1),

$x_{G P S}$ - $\mathrm{x}$ coordinate of aircraft based on the GPS solution, $y_{G L O}$ - y coordinate of aircraft based on the GLONASS solution, see Equation (1),

$y_{G P S}$ - y coordinate of aircraft based on the GPS solution, $z_{G L O}-\mathrm{z}$ coordinate of aircraft based on the GLONASS solution, see Equation (1),

$z_{G P S}-\mathrm{z}$ coordinate of aircraft based on the GPS solution. 


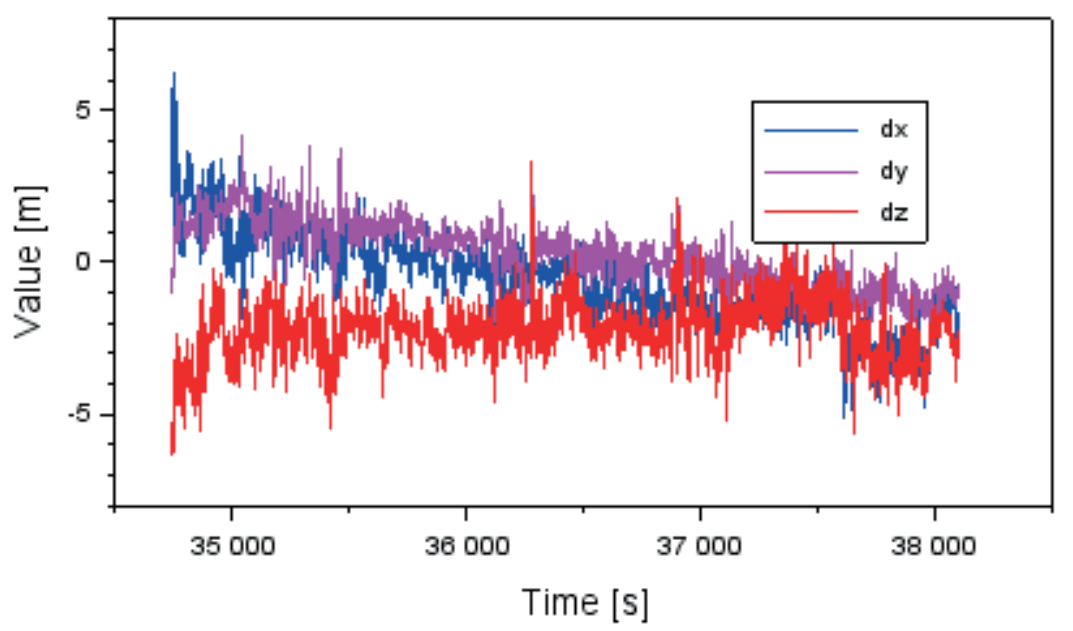

Figure 5 Comparison of the Cessna 172 coordinates based on the GLONASS and GPS data

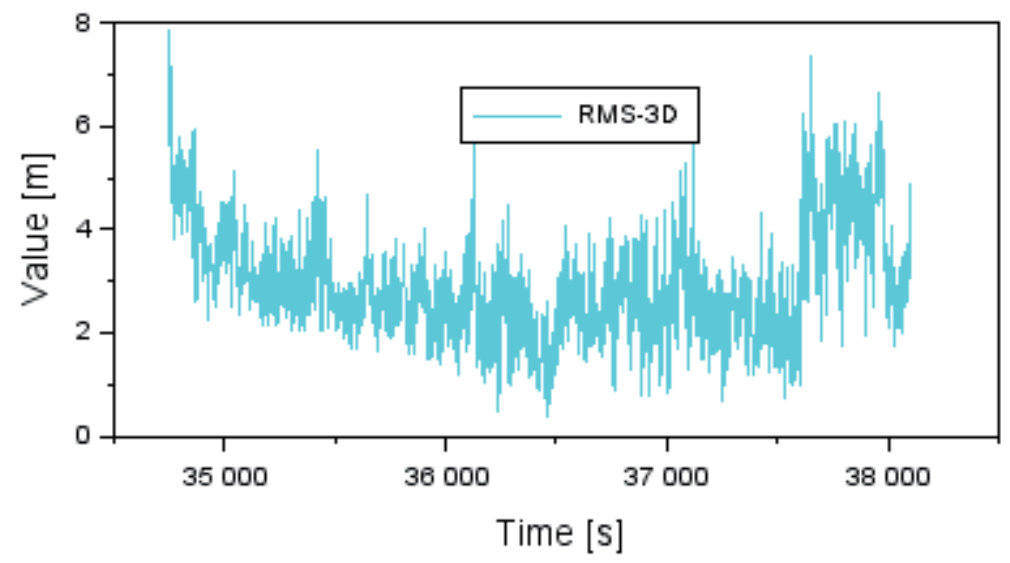

Figure 6 Results of the 3D-error parameter

Obtained values of the parameters $(d x, d y, d z)$ have been presented in Figure 5. The mean value of the parameter $d x$ is $-0.6 \mathrm{~m}$, with the RMS error being equal to $1.5 \mathrm{~m}$. Furthermore, the dispersion of the obtained parameter results $d x$ ranges from $-5.2 \mathrm{~m}$ to $+6.3 \mathrm{~m}$. The mean value of the parameter $d y$ is $+0.27 \mathrm{~m}$, with the RMS error being equal to $1.1 \mathrm{~m}$. Moreover, the dispersion of the obtained results of the parameter $d y$ ranges from $-2.5 \mathrm{~m}$ to $+4.2 \mathrm{~m}$. The mean value of the parameter $d z$ is $-2.2 \mathrm{~m}$, with the RMS error being equal to $1 \mathrm{~m}$. Besides that, the dispersion of the obtained results of the parameter $d z$ is between -6.4 and $+3.3 \mathrm{~m}$. The parameter of accuracy is one of the factors determining the quality of the satellite positioning in transport. It can be concluded that the accuracy of positioning is officially certified by the ICAO for the GLONASS system. For pilots, it is important information since it determines which GNSS navigation system can be used while executing the air operations. Besides that, the ICAO certification guarantees that the quality of the navigation data from the GLONASS satellite system is sufficient for proper navigation in the horizontal plane LNAV and in the vertical VNAV plane, respectively. Therefore, the limits of accuracy for the LNAV and VNAV navigation must have official recommendation to be used in the air transport.
In another accuracy test, the authors determined the shift vector of coordinates in the $3 \mathrm{D}$ space, between the GPS and GLONASS solutions, in the form of the 3D-error parameter, as below [19-20]:

$$
3 D-\text { error }=\sqrt{d x^{2}+d y^{2}+d z^{2}} .
$$

Values of the 3D-error parameter are presented graphically in Figure 6. Value of the 3D-error parameter ranges from $0.4 \mathrm{~m}$ to $7.9 \mathrm{~m}$. In addition, the mean value of the $3 \mathrm{D}$-error parameter is $2.9 \mathrm{~m}$, with the median being equal to $2.8 \mathrm{~m}$. It should be emphasized that approximately $17 \%$ of all the results of the 3D-error parameter do not exceed $2 \mathrm{~m}$, and approximately $85 \%$ of all the results of the 3D-error parameter do not exceed the limit of $4 \mathrm{~m}$.

\section{Conclusions}

The article assesses the accuracy and reliability of determining the position of the aircraft Cessna 172, using the positioning technique Difference Between Single Satellite (BSSD) in the GLONASS system. The numerical calculations were carried out in the author's original software Aircraft Positioning Software (APS), adapted to 
the development of the GNSS observations, for the needs of air navigation. In the numerical calculations, the authors used real GLONASS navigation data from the receiver Topcon HiperPro, mounted on board the aircraft Cessna 172. The article presents the values of standard deviations of the designated coordinates of the aircraft Cessna 172 in the XYZ geocentric frame, as well as of the MRSE position error. The values of standard deviations are under $2 \mathrm{~m}$. On the other hand, values of the MRSE parameter are less than $3 \mathrm{~m}$. Furthermore, in the article the authors verified the designated coordinates of the Cessna 172 in order to determine the accuracy of the research method. The article compares the coordinates of the Cessna 172 from the GLONASS and GPS solutions. The RMS error of comparing the coordinates of the Cessna 172 in the GPS and GLONASS solutions does not exceed $1.5 \mathrm{~m}$ along all the axes of the $\mathrm{XYZ}$ geocentric frame. The results of the research work on use of the GLONASS system in aviation are very promising. In the future, the authors plan to further develop the use of the GLONASS satellite navigation system for the air navigation.

\section{Acknowledgements}

This paper was supported by Polish Air Force University for 2019 year.

\section{References}

[1] MCCONNACHIE, D., BONNEFOY, P., BELLE, A. Investigating benefits from continuous climb operating concepts in the national airspace system: data and simulation analysis of operational and environmental benefits and impacts. 11th USA/Europe Air Traffic Management Research and Development Seminar ATM 2015: proceedings. 2015.

[2] ERRICO, A., VITO, V. D., FEDERICO, L. Study on continuous descent operation for efficient air transport system. 16th AIAA Aviation Technology, Integration, and Operations Conference : proceedings. 2016.

[3] NOVAK, D., BUCAK, T., RADISIC T. Development, Design and flight test evaluation of continuous descent approach procedure in FIR Zagreb. Promet - Traffic \& Transportation [online]. 2012, 21(5), p. 319-329. ISSN 0353-5320, eISSN 1848-4069. Available from: https://doi.org/10.7307/ptt.v21i5.247.

[4] ERRICO, A., DI VITO, V. Performance-based navigation (PBN) with continuous descent operations (CDO) for efficient approach over highly protected zones. 24th Saint Petersburg International Conference on Integrated Navigation Systems ICINS 2017 : proceedings [online]. 2017. ISBN 978-1-5386-0978-1. Available from: https://doi.org/10.23919/ICINS.2017.7995612.

[5] ICAO, ICAO standards and recommended practices (SARPS), annex 10 volume I (radio navigation aids) - ICAO [online]. 2006. [Viewed 2018-10-15]. Available from: www.ulc.gov.pl/pl/prawo/prawo-mi\%C4\%99dzynarodowe/206konwencje.

[6] KRASUSKI, K., WIERZBICKI D., JAFERNIK, H. Utilization PPP method in aircraft positioning in post-processing mode. Aircraft Engineering and Aerospace Technology [online]. 2018, 90(1), p. 202-209. ISSN 0002-2667. Available from: https://doi.org/10.1108/AEAT-05-2016-0078.

[7] WALTER, T., BLANCH, J., CHOI, M. J., REID, T., ENGE, P. Incorporating GLONASS into aviation RAIM receivers. International Technical Meeting of the Institute of Navigation : proceedings. 2013, p. 239-249.

[8] CHIN, G. Y., KRAEMER, J. H., NIM, G. C., VAN DYKE K. L. GPS/GLONASS RAIM augmentation to WAAS for CAT I precision approach. 53rd Annual Meeting of the Institute of Navigation : proceedings. 1997, p. 461-472.

[9] MISRA, P., PRATT, M., BURKE, B. Augmentation of GPS/LAAS with GLONASS: performance assessment. 11th International Technical Meeting of the Satellite Division of the Institute of Navigation : proceedings. 1998, p. 495-502.

[10] REDDY, G. S., SARASWAT, V. K. Advanced navigation system for aircraft applications. Defence Science Journal [online]. 2013, 63(2), p. 131-137. ISSN 0011-748X. Available from: https://doi.org/10.14429/dsj.63.4254.

[11] KRASUSKI, K., CWIKLAK, J. Application of the GLONASS code observations for the designation of coordinates of an aircraft in flight test mode: a case study. Scientific Journal of Silesian University of Technology. Series Transport [online]. 2017, 97, p. 69-80. ISSN 0209-3324, eISSN 2450-1549. Available from: https://doi.org/10.20858/sjsutst.2017.97.7

[12] BERAN, T. Single-frequency, single-receiver terrestrial and space borme point positioning. Technical Report no. 257, Department of Geodesy and Geomatics Engineering, University of New Brunswick, 2008, p. 34-36.

[13] SANZ SUBIRANA, J., JUAN ZORNOZA, J. M., HERNANDEZ-PAJARES, M. GNSS data processing. Volume I: Fundamentals and algorithms. Noordwijk, Netherlands: ESA Communications, ESTEC, 2013. ISBN 978-92-9221-886-7, p. 139-144.

[14] KRASUSKI, K. Aircraft positioning using SPP method in GPS system, Aircraft Engineering and Aerospace Technology [online]. 2018, 90(8), p. 1213-1220. ISSN 0002-2667. Available from: https://doi.org/10.1108/AEAT-03-2017-0087.

[15] OSADA, E. Geodesy (in Polish). Wroclaw: Oficyna Wydawnicza Politechniki Wroclawskiej, 2011. ISBN 83-7085-663-2, p. 237-241.

[16] SEEBER, G. Satellite geodesy. 2nd completely revised and extended edition. Berlin, Germany: Walter de Gruyter GmbH \& Co. KG, 2003. ISBN 3-11-017549-5, p. 300-303. 
[17] JOKInEN, A., FENG, S., Milner, C., SCHUSTER, W., OCHIENG, W., HIDE, C., MOORE, T., HILL, C. Precise point positioning and integrity monitoring with GPS and GLONASS. European Navigation Conference : proceedings. 2011, p. 1-12.

[18] BAKULA, M. Static code DGPS positioning based on three reference stations. Geodesy and Cartography. 2005, 54(2), p. 81-92. ISSN 1648-3502.

[19] PIRTI, A., YUCEL, M. A., GUMUS, K. Testing real time kinematic GNSS (GPS and GPS/GLONASS) methods in obstructed and unobstructed sites. Geodetski vestnik [online]. 2013, 57(3), p. 498-512. ISSN 0351-0271, e-ISSN 1581-1328. Available from: https://doi.org/10.15292/geodetski-vestnik.2013.03.498-512.

[20] RODRIGUEZ-BILBAO, I., RADICELLA, S. M., RODRIGUEZ-CADEROT, G., HERRAIZ, M. Precise point positioning performance in the presence of the 28 October 2003 sudden increase in total electron content. Space Weather [online]. 2015, 13, p. 698-708. ISSN 1539-4964. Available from: https://doi.org/10.1002/2015SW001201.

\section{Annex}

\begin{tabular}{|c|c|}
\hline Abbreviation & Full name \\
\hline GLONASS & Global Navigation Satellite System \\
\hline NAVSTAR GPS & NAVigational Satellite Time And Ranging Global Positioning System \\
\hline BSSD & Between Satellite Single Difference \\
\hline ICAO & International Civil Aviation Organization \\
\hline GNSS & Global Navigation Satellite System \\
\hline ABAS & Aircraft Based Augmentation System \\
\hline SBAS & Satellite Based Augmentation System \\
\hline GBAS & Ground Based Augmentation System \\
\hline RAIM & Receiver Autonomous Integrity Monitoring \\
\hline FMS & Flight Management System \\
\hline INS & Inertial Navigation System \\
\hline EPDE & ICAO airport code \\
\hline RIFCB & Receiver Inter-Frequency Code Bias \\
\hline SIFCB & Satellite Inter-Frequency Code Bias \\
\hline APS & Aircraft Positioning Software \\
\hline SPP & Single Point Positioning \\
\hline IF LC & Ionosphere-Free linear combination \\
\hline IGS & International GNSS Service \\
\hline ANTEX & Antenna Exchange Format \\
\hline RINEX & Receiver Independent Exchange System \\
\hline HPL & Horizontal Protection Level \\
\hline VPL & Vertical Protection Level \\
\hline DOP & Dilution of Precision \\
\hline GDOP & Geometric DOP \\
\hline PDOP & Position DOP \\
\hline VDOP & Vertical DOP \\
\hline HDOP & Horizontal DOP \\
\hline MRSE & Mean Radial Spherical Error \\
\hline LNAV & Lateral Navigation \\
\hline VNAV & Vertical Navigation \\
\hline
\end{tabular}

